\title{
Osteoporosis and autophagy: What is the relationship?
}

\author{
Rinaldo Florencio-Silva ${ }^{1 *}$, Gisela Rodrigues da Silva Sasso², Manuel de Jesus Simões ${ }^{3}$, Ricardo Santos Simões ${ }^{4}$, \\ Maria Cândida Pinheiro Baracat ${ }^{5}$, Estela Sasso-Cerri ${ }^{6}$, Paulo Sérgio Cerri ${ }^{6}$ \\ ${ }^{1}$ PhD, Postdoctoral Student, Department of Morphology and Genetics, Division of Histology and Structural Biology, Universidade Federal de São Paulo (Unifesp), São Paulo, SP, Brazil \\ ${ }^{2}$ PhD, Postdoctoral Student, Department of Gynecology, Unifesp, São Paulo, SP, Brazil \\ ${ }^{3}$ Full Professor of the Department of Morphology and Genetics, Division of Histology and Structural Biology, Unifesp, São Paulo, SP, Brazil \\ ${ }^{4} \mathrm{PhD}, \mathrm{MD}$, Department of Obstetrics and Gynecology, Faculdade de Medicina da Universidade de São Paulo (FMUSP), São Paulo, SP, Brazi \\ ${ }^{5}$ MSc Student, MD, Department of Obstetrics and Gynecology, FMUSP, São Paulo, SP, Brazil \\ ${ }^{6}$ PhD, Adjunct Professor (Habilitation: BR. Livre-docente) of the Department of Morphology, Laboratory of Histology and Embryology, Faculty of Dentistry of Araraquara, Universidade Estadual Paulista (Unesp), Araraquara, SP, Brazil
}

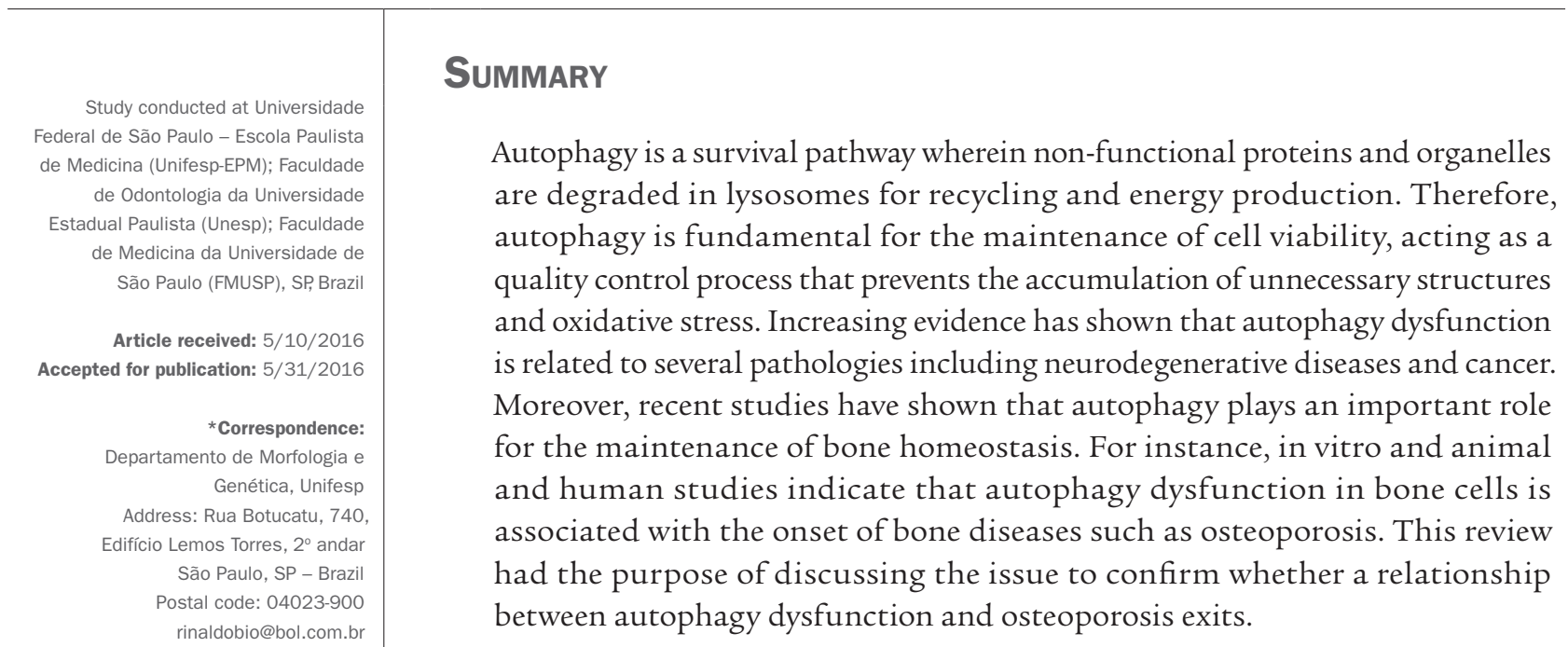

Keywords: autophagy, bone tissue, osteoblast, osteocyte, osteoclast, osteoporosis.

\section{INTRODUCTION}

Bone tissue is constantly being remodeled by the coordinated action of osteoclasts, osteoblasts, osteocytes, and bone lining cells. ${ }^{1,2}$ Osteoclasts and osteoblasts are respectively responsible for bone resorption and formation, while osteocytes are important in maintaining and controlling bone remodeling. ${ }^{2-5}$ Bone remodeling is necessary for the repair of microfractures, as well as for skeletal adaptation to different mechanical stimuli and for calcium homeostasis. ${ }^{6}$ However, any imbalance in this process so that bone reabsorption exceeds formation can result in bone loss and subsequent osteoporosis. ${ }^{7-10}$

Osteoporosis is a systemic bone disease characterized by progressive loss of bone mass, bone fragility and susceptibility to fractures. ${ }^{11}$ The incidence of osteoporotic fractures, associated with morbidity, mortality and the costs of these fractures, has increased substantially and became a public health problem in many countries, ${ }^{12-14}$ including Brazil. ${ }^{15-17}$ As life expectancy increases, the number of osteoporotic fractures is expected to increase from 1.7 million in 1990 to 6.3 million in $2050 .{ }^{18}$
The cause of osteoporosis is multifactorial and includes genetic, hormonal and nutritional factors, combined with people's lifestyle choices. ${ }^{19,20}$ Peak bone mass is reached early in adult life and from this point both men and women start to lose bone mass more or less depending on a combination of intrinsic and extrinsic factors. ${ }^{21,22}$ This process can be aggravated by a lack of physical exercise, ${ }^{23}$ prolonged treatment with corticoids, ${ }^{24}$ estrogen deficiency, especially in postmenopausal women, ${ }^{25}$ presence of other chronic diseases, and by aging. ${ }^{20}$

Recent evidence has pointed out that autophagy, a cell survival pathway, plays an important role in the maintenance of bone homeostasis, ${ }^{26-28}$ and changes in this pathway have been related to osteoporosis. ${ }^{29,30}$ Since osteoporosis became a serious public health problem with an incidence rate that is likely to increase in the next decades, understanding the cellular and molecular mechanisms involved in the process of bone loss is crucial and paramount for the development of new therapies.

In this review, we discuss studies that associate the autophagic pathway with osteoporosis, aiming to better 
understand if there is a possible correlation between these two processes.

\section{Autophagy}

Autophagy (from the Greek autos, self, and phagein, eat) is a lysosomal degradation pathway responsible for the degradation and recycling of cellular components such as unnecessary organelles and proteins, also serving to destroy intracellular pathogens. ${ }^{31-33}$ Autophagy occurs in every cell so that structures that are unnecessary to the cell can be recycled. However, factors that induce cellular stress, such as hypoxia, caloric restriction and the accumulation of oxidative stress, can induce autophagy. ${ }^{34-36}$

Three types of autophagy are described: macroautophagy, microautophagy and chaperone-mediated autophagy. The latter involves direct translocation of cytoplasmic proteins into lysosomes, aided and directed by chaperone proteins. ${ }^{37}$ In microautophagy, invagination of the lysosomal membrane results in small portions of the cytoplasm being captured towards the lysosome lumen. ${ }^{38,39}$ Macroautophagy, hereafter referred to as autophagy, is the most studied of the three autophagic pathways, it has been maintained throughout evolution, from yeast to mammals, and is characterized by the formation of autophagosomes. ${ }^{40,41}$ After autophagic stimulation, a small vesicle called the phagophore elongates and subsequently surrounds a portion of the cytoplasm, resulting in the formation of a double membrane structure, termed autophagosome..$^{31,42}$ The membrane of the autophagosome then fuses with a lysosome, resulting in the degradation of the entrapped material. Amino acids, fatty acids and other molecules resulting from degradation return to the cytoplasm for recycling and energy production. ${ }^{38,42}$

Usually, the autophagic process is divided into four main steps: initiation/nucleation, elongation, maturation and degradation. ${ }^{38,42}$ During initiation, which takes place after autophagic stimulus, a membrane known as phagophore is formed. Phagophore formation and nucleation occur with the formation of two multiprotein complexes: one is composed of proteins ULK1/2, Atg13 and FIP200, and the other, which is known as class III phosphatidylinositol 3-kinase (PI3K) complex, is formed by proteins beclin-1, Vps15, Vps34, Ambra1, UVRAG, and more. ${ }^{33,43}$ These complexes, with the participation of several other proteins, are responsible for recruiting and initiating phagophore elongation. ${ }^{44}$ Beclin-1 is fundamental for the formation of PI3K complexes and, therefore, has been commonly used as a marker of autophagia. ${ }^{45}$

After nucleation, phagophore elongation occurs and an autophagosome is formed. This process is coordi- nated by two protein complexes called ubiquitin-like conjugation system, formed by several Atgs (autophagy-related genes) proteins, including Atg3, Atg4, Atg5, Atg7, Atg10, Atg12 and Atg16. This system facilitates conjugation of a molecule called LC3 (a light chain of the microtubule-associated protein 1) with phospholipid phosphatidylethanolamine to LC3II. LC3II then enters the autophagosome's membrane, assisting its elongation and closure. ${ }^{38,46}$ Therefore, it is currently known that LC3II is found within the autophagosome's membrane, being key to its formation. Because of that, LC3II has been widely used as a specific autophagosome marker. ${ }^{38,47}$

The other stages of autophagy consist in autophagosome maturation and degradation of its contents. Autophagosome maturation refers to its fusion with components of the endocytic pathway, such as early and late endosomes and lysosomes, turning the contents inside the autophagosome acid. ${ }^{48}$ Several proteins involved in vesicular transport, such as dynein, and membrane fusion in the endocytic pathway, including Rab7, SNARES and ESCRT, beclin-1, Vps34 and UVRAG, are involved in autophagosome maturation. ${ }^{49}$ The last stage of the autophagic pathway is that of degradation of the autophagosome's contents after fusing with a lysosome and subsequent reuse of the resulting molecules (lipids, amino acids, nucleotides, etc.) as a manner of recycling cell components and producing energy. ${ }^{50}$

For a long time, autophagy was considered a pathway of non-selective degradation. ${ }^{48}$ However, it is currently accepted that this process can be extremely specific since organelles are selectively targeted for degradation. ${ }^{51}$ The most widely known example of protein-specific autophagic degradation is that of protein p62 (ou SQSTM1), which binds to ubiquitinated proteins leading them to the interior of autophagosomes. ${ }^{52}$ This mechanism is mediated by binding of p62 to LC3II present in the autophagosome's membrane, so that p62 is also internalized and ultimately degraded. This protein is thus considered as one of the main substrates for autophagosomes and, therefore, its increased expression indicates decline in the autophagic process and vice versa. Analyses of the combined expression of proteins p62 and LC3II are commonly used to assess the autophagic flow in cells. ${ }^{53,54} \mathrm{~A}$ summary of the major stages of the autophagic pathway is illustrated in Figure 1.

\section{ROLE OF AUTOPHAGY IN BONE BIOLOGY}

In recent years, a growing number of studies has shown that autophagy plays an important role to maintain bone homeostasis. ${ }^{26,27,55}$ For example, cultures of autophagy 


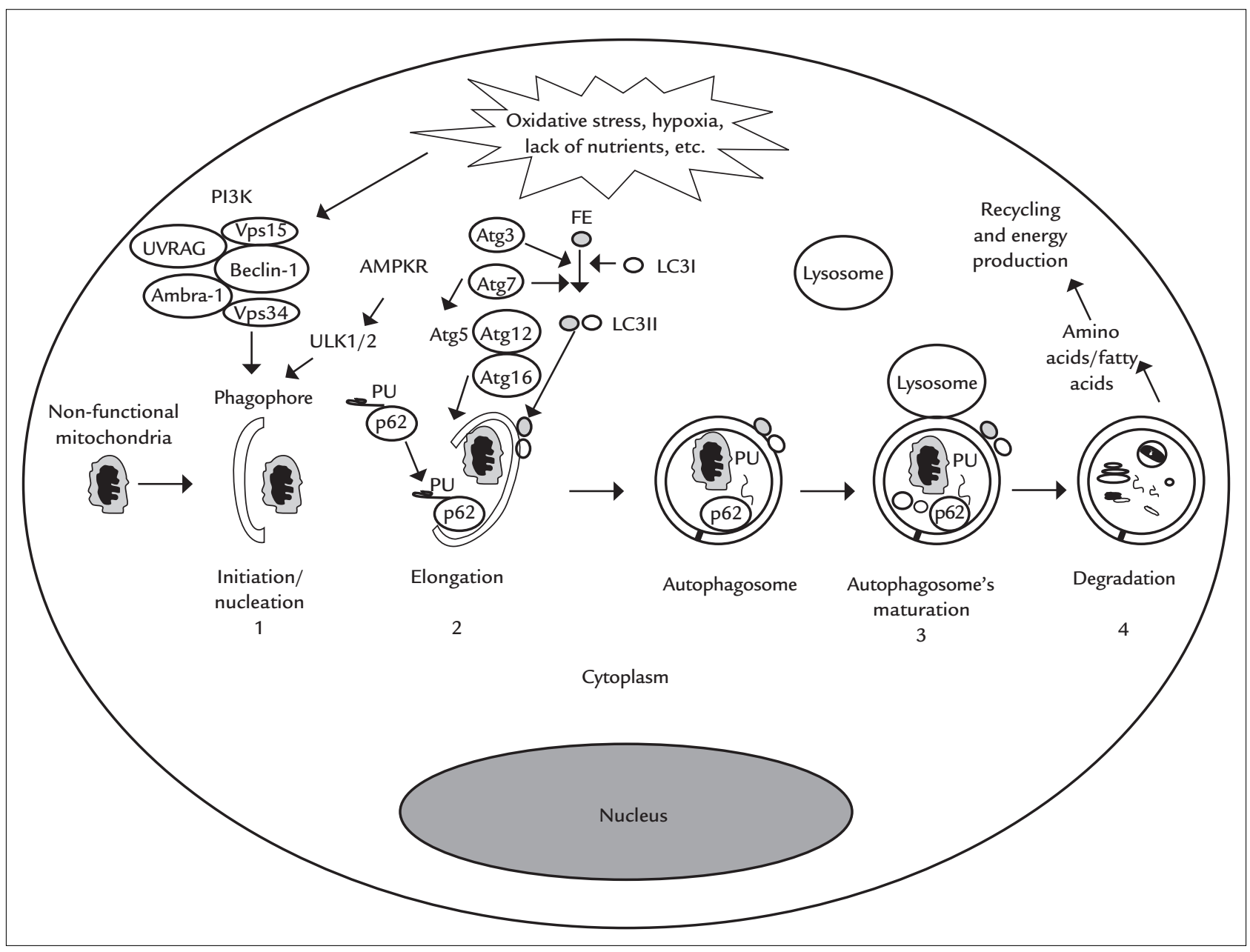

FIGURE 1 Schematic model of the four main stages of the autophagic pathway: 1. initiation/nucleation; 2. elongation; 3. maturation; and 4. degradation. After autophagic stimulation (oxidative stress, hypoxia, lack of nutrients, etc.), phagosome formation/nucleation is observed (1), assisted by multiprotein complexes PI3K (formed by beclin-1, Vps34/15, Ambra-1 and UVRAG) and ULK1/ULK2, as well as Atgs. Assisted by protein LC3II, the phagophore elongates and circles organelles and proteins that are no longer functional (2), including polyubiquitinated proteins (PU) carried by p62, forming the autophagosome. The latter may fuse with a lysosome (3), so that its contents are degraded (4).

gene-knockout osteoblasts (BECN-1, ATG7 e LC3) result in deficiency in the process of mineralization. ${ }^{56}$

In vitro studies show that pharmacological inhibition of autophagy in osteoblast-like cells increases oxidative stress and stimulates apoptosis in these cells. In contrast, induction of autophagy in cultures of osteoblast-like cells reduces their oxidative stress and inhibits apoptosis. ${ }^{57} \mathrm{It}$ has also been reported that estrogen inhibits osteoblast apoptosis in vitro, inducing autophagy in these cells. ${ }^{58}$

Autophagy is also essential when osteoblasts are incorporated into the bone matrix, thus becoming osteocytes. ${ }^{59}$ During the transition, osteoblasts undergo evident changes in their shape, accompanied by a significant reduction in the number and size of organelles. ${ }^{60} \mathrm{It}$ is assumed that an increase in the autophagic process occurs during this transition from osteoblasts to osteocytes. This increase is due to the need for faster organelle recycling and preservation of nutrients, while the cell develops its actin-rich prolongations, and adjusts to an environment more susceptible to hypoxia. ${ }^{59} \mathrm{In}$ fact, the expression of LC3 in osteocytes is greater than in osteoblasts. ${ }^{61}$

Osteocytes are long-lived cells located in gaps delimited by mineralized bone matrix and, consequently, are positioned in an environment more susceptible to hypoxia and to the accumulation of oxidative stress. ${ }^{55}$ It is believed that under these conditions autophagy plays an important role in the survival of osteocytes. ${ }^{59}$ Osteocyte-like cells have increased autophagic activity after undergoing nutrient deprivation and hypoxia in vitro, conditions that are similar to those found in osteocytes in vivo. In addition, in 
response to calcium-mediated stress, a hypoxia-inducing transcription factor (HIF-1) positively regulates autophagy, indicating that low oxygen tension serves as a regulator of autophagy in this type of cell. ${ }^{61}$ Low-dose glucocorticoid treatment has also been shown to induce autophagy in osteocytes in response to increased oxidative stress caused by treatment, preserving the viability of these cells. ${ }^{62-64}$

Studies indicate that autophagy also plays an important role in bone resorption by osteoclasts. ${ }^{65}$ It has been reported that proteins involved in the autophagic pathway are important in the regulation of osteoclastogenesis, ${ }^{66,67}$ indicating that this process participates both in bone formation and resorption. There is evidence that resorptive activity is decreased when bafilomycin, an autophagy inhibitor, is added to the culture of osteoclasts. ${ }^{68,69}$ In mice, a mutation in the gene encoding the $\mathrm{p} 62$ protein has also been reported to result in a phenotype similar to Paget's bone disease, a condition in which there is excessive increase in bone remodeling and susceptibility to fractures. ${ }^{70}$ In addition, it has been reported that an increase in autophagy occurs during osteoclastogenesis under conditions of hypoxia and increased oxidative stress caused by glucocorticoid treatment. In this case, it was suggested that autophagy would act as a protective factor reducing cell stress, increasing the formation and viability of osteoclasts. ${ }^{7-73}$

Deletions in genes encoding key proteins in the formation of the autophagosome (ATG5, ATG7, ATG4B and LC3) have been shown to cause changes in the brush border formation of osteoclasts, and, consequently, to reduce bone resorption and increase bone volume, thus preventing bone loss in mice after ovariectomy. ${ }^{65}$ Some authors suggest that inhibition of autophagy in osteoclasts may serve as a possible therapeutic mechanism against bone diseases in which there is an excessive increase in bone resorption. ${ }^{55,72}$ In fact, it has recently been observed in mice that pharmacological and genetic inhibition of autophagy reduces osteoclastogenesis and bone resorption, inhibiting bone loss caused by ovariectomy or glucocorticoid treatment. ${ }^{74}$

Recently, autophagy has also been pointed as an important factor in the process of bone growth. It was observed that the secretion of type II collagen by chondrocytes of the epiphyseal disc of mice is regulated by autophagy, under the influence of fibroblast growth factor 18 (FGF18) ${ }^{28}$ However, the mechanisms by which autophagy regulates the secretion of type II collagen during bone growth are still not fully understood. A clinical trial of gene screening that included 618 adult Chinese subjects demonstrated that the expression of genes regulating the autophagic pathway may influence stature variation in this population. ${ }^{75}$ Considering that autophagy increases the viability of chondrocytes, the authors report that this influence can be attributed to the protective role that autophagy exerts on these cells in the epiphyseal disc, thus influencing the growth of long bones. ${ }^{76}$

Other recent studies indicate that the activation of autophagy is also associated with the repair process of bone fractures. ${ }^{77,78}$ In this case, it has been proposed that the increase in autophagy that occurs after a bone injury would act as a defense mechanism of the bone cells against cell stress, caused by the sudden reduction or interruption of the nutrient supply, due to bone fracture. ${ }^{78}$ Thus, studies indicate that autophagy is a crucial factor for the maintenance of bone tissue homeostasis.

\section{AUTOPHAGY, BONE LOSS AND OSTEOPOROSIS: What IS THE EVIDENCE?}

It has been widely reported that dysfunction in the autophagic pathway is involved in the development of various pathologies such as: neurodegenerative (e.g. Alzheimer's and Parkinson's) ${ }^{79}$ and vascular ${ }^{80}$ diseases, cancer, ${ }^{81}$ diabetes, ${ }^{82}$ obesity, ${ }^{83}$ rheumatoid arthritis, ${ }^{84}$ and osteoarthritis. ${ }^{85}$ Studies suggest that dysregulation of autophagy may also be associated with the process of bone loss and subsequent osteoporosis. ${ }^{27,86}$

Recently, pharmacological inhibition with chloroquine and genetic inhibition by the selective deletion of the Atg7 gene in monocytes have been shown to reduce osteoclastogenesis and decrease bone loss in animal models. ${ }^{74,87}$ Administration of an antibody against sclerostin, an inhibitor of bone formation by osteoblasts, was able to prevent bone loss promoted by treatment with glucocorticoids in male mice. ${ }^{88}$ In the study, treatment with high doses of glucocorticoids reduced the percentage of LC3-positive osteoblasts, an autophagic marker, thus reducing the viability of these cells and causing bone loss. Treatment with anti-sclerostin antibody, in turn, maintained the viability of osteoblasts by increasing autophagy in these cells and reducing bone loss caused by glucocorticoid treatment. ${ }^{88}$ However, further studies are needed to understand the specific mechanisms by which sclerostin, or its antibody, regulates the autophagic pathway in bone cells.

Such findings indicate that autophagy contributes to the maintenance of bone mass, in part by maintaining the viability of osteoblasts. According to this idea, a deletion of the FIP200 gene (essential for autophagosome formation) in osteoblasts has been reported to cause osteopenia in rats due to the decrease in bone formation by these cells. ${ }^{89}$

In osteocytes, the deletion of the Atg7 gene (essential for autophagy initiation) has been shown to promote 
bone mass decrease in 6-month-old male and female mice, similar to that caused by natural aging. ${ }^{86}$ In another study, a relationship was observed between decreased autophagic activity in osteocytes and bone loss during aging in senile rat models. ${ }^{29}$ Recently, this result has also been achieved in senile rat models in which rapamycin, an autophagy inducer, reduced osteoporosis by activating autophagy in osteocytes. ${ }^{30}$

These studies indicate that the mechanism by which autophagy reduces the bone loss caused by aging in these models seems to be related to the antioxidant effect of autophagy on bone cells. The fact that oxidative stress was higher in knockout animal models for Atg7 reinforces this hypothesis. ${ }^{86}$ Also, although estrogen deficiency is considered a major cause of bone loss and osteoporosis in postmenopausal women, studies have shown that increased oxidative stress in bone tissue is one of the major contributing factors to bone loss caused by aging. ${ }^{59,90,91}$

In short, the reduction of autophagy appears to promote increased oxidative stress, causing bone loss, whereas an increase in the autophagic pathway inhibits this effect. ${ }^{29,30,86}$ According to this hypothesis, a significant inverse correlation was observed between the level of autophagy in osteocytes and the oxidative stress and bone loss caused by estrogen deficiency in the tibia of ovariectomized rats. ${ }^{92}$

Most evidence indicating a possible relationship between autophagic dysfunction and osteoporosis arises from studies in animal and in vitro models. In humans, however, there is still very little evidence to indicate such a relationship. A genetic screening study in humans revealed that, among the different pathways studied, the expression of autophagic pathway regulatory genes was the only one that showed a direct relationship with the variation in bone mineral density in the distal portion of the radius in 984 individuals. ${ }^{93}$ The authors concluded that this relationship may indicate an important participation of the autophagic pathway in the development of osteoporosis.

The preclinical in vivo and in vitro studies included in our review indicate a relationship between the dysregulation of the autophagic pathway and osteoporosis. This possible relationship is summarized in Figure 2.

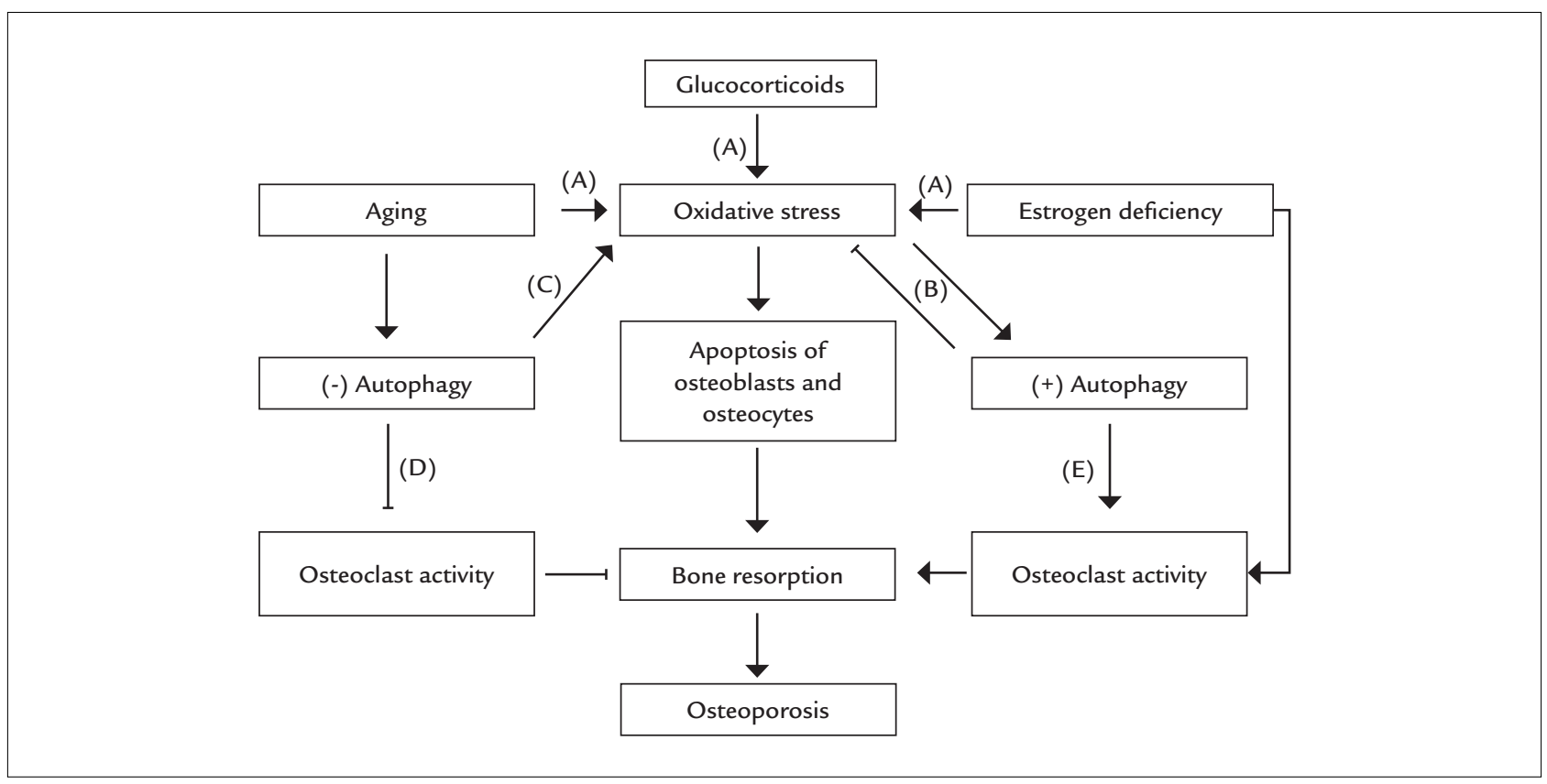

FIGURE 2 Diagram illustrating the possible relationships between autophagy and osteoporosis. (A) Aging, prolonged treatment with glucocorticoids and estrogen deficiency increase oxidative stress in bone tissue, inducing apoptosis of osteoblasts and osteocytes and increased bone resorption by osteoclasts, which induces bone loss and osteoporosis. (B) On the other hand, increased oxidative stress stimulates the autophagic (+) pathway, which reduces the deleterious effect of stress by degrading damaged proteins and organelles. Reduction of cell stress inhibits the apoptosis of osteoblasts and osteocytes, decreasing bone loss and osteoporosis. A reduction of autophagy (-) caused by aging results in increased oxidative stress (C), which can cause bone loss and subsequent osteoporosis. Autophagy is also essential for the viability of osteoclasts. Thus, while the reduction of autophagy decreases the formation and resorptive activity of these cells (D), the increase of autophagy stimulates these processes $(\mathrm{E})$. Arrows indicate stimulatory action and bars indicate inhibitory action. 


\section{Conclusion}

In conclusion, based on experimental in vivo and in vitro studies, there is a number of evidences that reinforce the existence of a correlation between the autophagy process and osteoporosis. Nevertheless, future studies, especially clinical trials, are needed to confirm the possible relationship between autophagic dysfunction and osteoporosis in humans, as well as to develop future therapies for the prevention and/or treatment of osteoporosis.

\section{Resumo}

Osteoporose e autofagia: qual é a relação?

A autofagia é uma via de sobrevivência celular pela qual proteínas e organelas não funcionais são degradadas nos lisossomos, para reciclagem e geração de energia. Assim, a autofagia é fundamental para a manutenção da homeostase e viabilidade da célula, agindo como um controle de qualidade que evita o acúmulo de estruturas desnecessárias e o estresse oxidativo. Um número crescente de estudos tem demonstrado que disfunções na via autofágica estão relacionadas ao surgimento de diversas doenças, como as neurodegenerativas e o câncer. Estudos também têm indicado que a autofagia exerce um importante papel para a manutenção da homeostase óssea; por exemplo, estudos in vitro e em animais e humanos mostram que disfunções da autofagia nas células ósseas estão associadas ao surgimento de doenças ósseas, como a osteoporose. Nesta revisão, foram abordados esses estudos, a fim de melhor esclarecer se há uma relação entre disfunção autofágica e osteoporose.

Palavras-chave: autofagia, tecido ósseo, osteoblasto, osteócito, osteoclasto, osteoporose.

\section{RefEREnCES}

1. Crockett JC, Rogers MJ, Coxon FP, Hocking LJ, Helfrich MH. Bone remodelling at a glance. J Cell Sci. 2011; 124(Pt 7):991-8.

2. Florencio-Silva R, Sasso GRS, Sasso-Cerri E, Simões MJ, Cerri PS. Biology of bone tissue: structure, function, and factors that influence bone cells Biomed Res Int. 2015; 2015:421746.

3. Teitelbaum SL. Osteoclasts: what do they do and how do they do it? Am J Pathol. 2007; 170(2):427-35.

4. Karsenty G, Kronenberg HM, Settembre C. Genetic control of bone formation. Annu Rev Cell Dev Biol. 2009; 25:629-48.

5. Bonewald LF. The amazing osteocyte. J Bone Miner Res. 2011; 26(2):229-38

6. Dallas SL, Prideaux M, Bonewald LF. The osteocyte: an endocrine cell ... and more. Endocr Rev. 2013; 34(5):658-90

7. Mosley JR. Osteoporosis and bone functional adaptation: mechanobiological regulation of bone architecture in growing and adult bone, a review. J Rehabil Res Dev. 2000; 37(2):189-99.

8. Daci E, van Cromphaut S, Bouillon R. Mechanisms influencing bone metabolism in chronic illness. Horm Res. 2002; 58(Suppl 1):44-51.
9. Shankar Y, Misra S, Vineet D, Baskaran P. Paget disease of bone: a classic case report. Contemp Clin Dent. 2013; 4(2):227-30.

10. Shao B, Liao L, Yu Y, Shuai Y, Su X, Jing H, et al. Estrogen preserves Fas ligand levels by inhibiting microRNA-181a in bone marrow-derived mesenchymal stem cells to maintain bone remodelling balance. FASEB J 2015; 29(9):3935-44.

11. National Osteoporosis Society; 2013. Available from: http://www.nos.org.uk/.

12. Kanis JA, Johnell O. Requirements for DXA for the management of osteoporosis in Europe. Osteoporos Int. 2005; 16(3):229-38.

13. Lerner UH. Bone remodeling in post-menopausal osteoporosis. J Dent Res. 2006; 85(7):584-95

14. Das S, Crockett JC. Osteoporosis - a current view of pharmacological prevention and treatment. Drug Des Devel Ther. 2013; 7:435-48.

15. Pinheiro MM, Eis SR. Epidemiology of osteoporotic fractures in Brazil: what we have and what we need. Arq Bras Endocrinol Metabol. 2010; 54(2):164-70.

16. Marinho BC, Guerra LP, Drummond JB, Silva BC, Soares MM. The burden of osteoporosis in Brazil. Arq Bras Endocrinol Metabol. 2014; 58(5):434-43

17. Baccaro LF, Conde DM, Costa-Paiva L, Pinto-Neto AM. The epidemiology and management of postmenopausal osteoporosis: a viewpoint from Brazil. Clin Interv Aging. 2015; 10:583-91

18. Sambrook P, Cooper C. Osteoporosis. Lancet. 2006; 367(9527):2010-8.

19. Tella SH, Gallagher JC. Prevention and treatment of postmenopausal osteoporosis. J Steroid Biochem Mol Biol. 2014; 142:155-70.

20. Klein-Nulend J, van Oers RF, Bakker AD, Bacabac RG. Bone cell mechanosensitivity, estrogen deficiency, and osteoporosis. J Biomech. 2015; 48(5):855-65.

21. Raisz L, Seeman E. Causes of age related bone loss and bone fragility: an alternative view. J Bone Miner Res. 2001; 16(11):1948-52

22. Demontiero O, Vidal C, Duque G. Aging and bone loss: new insights for the clinician. Ther Adv Musculoskelet Dis. 2012; 4(2):61-76.

23. Hamrick I, Schrager S, Nye AM. Treatment of osteoporosis: current state of the art. Wien Med Wochenschr. 2015; 165(3-4):54-64.

24. Whittier X, Saag KG. Glucocorticoid-induced osteoporosis. Rheum Dis Clin North Am. 2016; 42(1):177-89.

25. Khosla S, Oursler MJ, Monroe DG. Estrogen and the skeleton. Trends Endocrinol Metab. 2012; 23(11):576-81.

26. Shapiro IM, Layfield R, Lotz M, Settembre C, Whitehouse C. Boning up on autophagy: the role of autophagy in skeletal biology. Autophagy. 2014; 10(1):7-19

27. Pierrefite-Carle V, Santucci-Darmanin S, Breuil V, Camuzard O, Carle GF. Autophagy in bone: self-eating to stay in balance. Ageing Res Rev. 2015; 24(Pt B):206-17.

28. Greenhill C. Bone: autophagy regulates bone growth in mice. Nat Rev Endocrinol. 2016; 12(1):4.

29. Chen K, Yang YH, Jiang SD, Jiang LS. Decreased activity of osteocyte autophagy with aging may contribute to the bone loss in senile population. Histochem Cell Biol. 2014; 142(3):285-95.

30. Luo D, Ren H, Li T, Lian K, Lin D. Rapamycin reduces severity of senile osteoporosis by activating osteocyte autophagy. Osteoporos Int. 2016; 27(3):1093-101.

31. Levine B, Klionsky DJ. Development by self-digestion: molecular mechanisms and biological functions of autophagy. Dev Cell. 2004; 6(4):463-77.

32. Kroemer G. Autophagy: a druggable process that is deregulated in aging and human disease. J Clin Invest. 2015; 125(1):1-4.

33. Zhang $\mathrm{H}$, Baehrecke $\mathrm{EH}$. Eaten alive: novel insights into autophagy from multicellular model systems. Trends Cell Biol. 2015; 25(7):376-87.

34. Cuervo AM. Autophagy and aging: keeping that old broom working. Trends Genet. 2008; 24(12):604-12.

35. Filomeni G, De Zio D, Cecconi F. Oxidative stress and autophagy: the clash between damage and metabolic needs. Cell Death Differ. 2015; 22:377-88.

36. Maiuri MC, Kroemer G. Autophagy in stress and disease. Cell Death Differ. $2015 ; 22(3): 365-6$.

37. Cuervo AM, Wong E. Chaperone-mediated autophagy: roles in disease and aging. Cell Res. 2014; 24(1):92-104

38. Mizushima N, Yoshimori T, Levine B. Methods in mammalian autophagy research. Cell. 2010; 140(3):313-26.

39. Li WW, Li J, Bao JK. Microautophagy: lesser-known self-eating. Cell Mol Life Sci. 2012; 69(7):1125-36.

40. Klionsky DJ. Autophagy: from phenomenology to molecular understanding in less than a decade. Nat Rev Mol Cell Biol. 2007; 8(11):931-7.

41. Reggiori F, Klionsky DJ. Autophagic processes in yeast: mechanism, machinery and regulation. Genetics. 2013; 194(2):341-61. 
42. Feng Y, He D, Yao Z, Klionsky DJ. The machinery of macroautophagy. Cell Res. 2014; 24(1):24-41.

43. Mizushima N, Levine B, Cuervo AM, Klionsky DJ. Autophagy fights disease through cellular self-digestion. Nature. 2008; 451(7182):1069-75.

44. Simonsen A, Tooze SA. Coordination of membrane events during autophagy by multiple class III PI3-kinase complexes. J Cell Biol. 2009; 186(6):773-82

45. Fu LL, Cheng Y, Liu B. Beclin-1: autophagic regulator and therapeutic target in cancer. Int J Biochem Cell Biol. 2013; 45(5):921-4.

46. Lamb CA, Yoshimori T, Tooze SA. The autophagosome: origins unknown, biogenesis complex. Nat Rev Mol Cell Biol. 2013; 14(12):759-74.

47. Klionsky DJ, Abdalla FC, Abeliovich H, Abraham RT, Acevedo-Arozena A Adeli K, et al. Guidelines for the use and interpretation of assays for monitoring autophagy. Autophagy. 2012; 8(4):445-544.

48. Ravikumar B, Sarkar S, Davies JE, Futter M, Garcia-Arencibia M, GreenThompson ZW, et al. Regulation of mammalian autophagy in physiology and pathophysiology. Physiol Rev. 2010; 90(4):1383-435.

49. Mehrpour M, Esclatine A, Beau I, Codogno P. Overview of macroautophagy regulation in mammalian cells. Cell Res. 2010; 20(7):748-62.

50. Rabinowitz JD, White E. Autophagy and metabolism. Science. 2010; 330(6009):1344-8

51. Xu Z, Yang L, Xu S, Zhang Z, Cao Y. The receptor proteins: pivotal roles in selective autophagy. Acta Biochim Biophys Sin (Shanghai). 2015; 47(8):571-80.

52. Lippai M, Löw P. The role of the selective adaptor p62 and ubiquitin-like proteins in autophagy. Biomed Res Int. 2014; 2014:832704.

53. Ichimura Y, Komatsu M. Selective degradation of $\mathrm{p} 62$ by autophagy. Semin Immunopathol. 2010; 32(4):431-6.

54. Schläfli AM, Berezowska S, Adams O, Langer R, Tschan MP. Reliable LC3 and $\mathrm{p} 62$ autophagy marker detection in formalin fixed paraffin embedded human tissue by immunohistochemistry. Eur J Histochem. 2015; 59(2):2481.

55. Hocking LJ, Whitehouse C, Helfrich MH. Autophagy: a new player in skeletal maintenance? J Bone Miner Res. 2012; 27(7):1439-47.

56. Nollet M, Santucci-Darmanin S, Breuil V, Al-Sahlanee R, Cros C, Topi M et al. Autophagy in osteoblasts is involved in mineralization and bone homeostasis. Autophagy. 2014; 10(11):1965-77.

57. Yang YH, Li B, Zheng XF, Chen JW, Chen K, Jiang SD, et al. Oxidative damage to osteoblasts can be alleviated by early autophagy through the endoplasmic reticulum stress pathway - implications for the treatment of osteoporosis Free Radic Biol Med. 2014; 77:10-20.

58. Yang YH, Chen K, Li B, Chen JW, Zheng XF, Wang YR, et al. Estradiol inhibits osteoblast apoptosis via promotion of autophagy through the ER-ERK-mTOR pathway. Apoptosis. 2013; 18(11):1363-75.

59. Manolagas SC, Parfitt AM. What old means to bone. Trends Endocrinol Metab. 2010; 21(6):369-74.

60. Dallas SL, Bonewald LF. Dynamics of the transition from osteoblast to osteocyte. Ann N Y Acad Sci. 2010; 1192:437-43.

61. Zahm AM, Bohensky J, Adams CS, Shapiro IM, Srinivas V. Bone cell autophagy is regulated by environmental factors. Cells Tissues Organs. 2011; 194(2-4):274-8.

62. Xia X, Kar R, Gluhak-Heinrich J, Yao W, Lane NE, Bonewald LF, et al. Glucocorticoid-induced autophagy in osteocytes. J Bone Miner Res. 2010; 25(11):2479-88

63. Jia J, Yao W, Guan M, Dai W, Shahnazari M, Kar R, et al. Glucocorticoid dose determines osteocyte cell fate. FASEB J. 2011; 25(10):3366-76

64. Yao W, Dai W, Jiang JX, Lane NE. Glucocorticoids and osteocyte autophagy. Bone. 2013; 54(2):279-84

65. DeSelm CJ, Miller BC, Zou W, Beatty WL, van Meel E, Takahata Y, et al Autophagy proteins regulate the secretory component of osteoclastic bone resorption. Dev Cell. 2011; 21(5):966-74.

66. Li RF, Chen G, Ren JG, Zhang W, Wu ZX, Liu B, et al. The adaptor protein p62 is involved in RANKL-induced autophagy and osteoclastogenesis. J Histochem Cytochem. 2014; 62(12):879-88.

67. Chung YH, Jang Y, Choi B, Song DH, Lee EJ, Kim SM, et al. Beclin-1 is required for RANKL-induced osteoclast differentiation. J Cell Physiol. 2014; 229(12):1963-71.

68. Nielsen RH, Karsdal MA, Sørensen MG, Dziegiel MH, Henriksen K. Dissolution of the inorganic phase of bone leading to release of calcium regulates osteoclast survival. Biochem Biophys Res Commun. 2007; 360(4):834-9.

69. Neutzsky-Wulff AV, Sørensen MG, Kocijancic D, Leeming DJ, Dziegiel MH, Karsdal MA, et al. Alterations in osteoclast function and phenotype induced by different inhibitors of bone resorption - implications for osteoclast quality. BMC Musculoskelet Disord. 2010; 11:109.

70. Daroszewska A, van 't Hof RJ, Rojas JA, Layfield R, Landao-Basonga E, Rose $\mathrm{L}$, et al. A point mutation in the ubiquitin-associated domain of SQSMT1 is sufficient to cause a Paget's disease-like disorder in mice. Hum Mol Genet. 2011; 20(14):2734-44.

71. Wang K, Niu J, Kim H, Kolattukudy PE. Osteoclast precursor differentiation by MCPIP via oxidative stress, endoplasmic reticulum stress, and autophagy J Mol Cell Biol. 2011; 3(6):360-8.

72. Zhao Y, Chen G, Zhang W, Xu N, Zhu JY, Jia J, et al. Autophagy regulates hypoxia-induced osteoclastogenesis through the HIF-1alpha/BNIP3 signaling pathway. J Cell Physiol. 2012; 227(2):639-48.

73. Shi J, Wang L, Zhang H, Jie Q, Li X, Shi Q, et al. Glucocorticoids: dose-related effects on osteoclast formation and function via reactive oxygen species and autophagy. Bone. 2015; 79:222-32.

74. Lin NY, Chen CW, Kagwiria R, Liang R, Beyer C, Distler A, et al. Inactivation of autophagy ameliorates glucocorticoid-induced and ovariectomy-induced bone loss. Ann Rheum Dis. 2016; 75(6):1203-10.

75. Pan F, Liu XG, Guo YF, Chen Y, Dong SS, Qiu C, et al. The regulation-of-autophagy pathway may influence Chinese stature variation: evidence from elder adults. J Hum Genet. 2010; 55(7):441-7.

76. Srinivas V, Shapiro IM. Chondrocytes embedded in the epiphyseal growth plates of long bones undergo autophagy prior to the induction of osteogenesis. Autophagy. 2006; 2(3):215-6.

77. Zhou Q, Luo D, Li T, Liu Z, Zou W, Wang L, et al. Bone fracture in a rat femoral fracture model is associated with the activation of autophagy. Exp Ther Med. 2015; 10(5):1675-80.

78. Yang GE, Duan X, Lin D, Li T, Luo D, Wang L, et al. Rapamycin-induced autophagy activity promotes bone fracture healing in rats. Exp Ther Med. 2015; 10(4):1327-33.

79. Kiriyama $\mathrm{Y}$, Nochi $\mathrm{H}$. The function of autophagy in neurodegenerative diseases. Int J Mol Sci. 2015; 16(11):26797-812.

80. De Meyer GR, Grootaert MO, Michiels CF, Kurdi A, Schrijvers DM, Martinet W. Autophagy in vascular disease. Circ Res. 2015; 116(3):468-79.

81. Ozpolat B, Benbrook DM. Targeting autophagy in cancer management strategies and developments. Cancer Manag Res. 2015; 7:291-9.

82. Barlow AD, Thomas DC. Autophagy in diabetes: $\beta$-cell dysfunction, insulin resistance, and complications. DNA Cell Biol. 2015; 34(4):252-60.

83. Nuñez CE, Rodrigues VS, Gomes FS, Moura RF, Victorio SC, Bombassaro $B$, et al. Defective regulation of adipose tissue autophagy in obesity. Int J Obes (Lond). 2013; 37(11):1473-80.

84. Dai Y, Hu S. Recent insights into the role of autophagy in the pathogenesis of rheumatoid arthritis. Rheumatology (Oxford). 2016; 55(3):403-10.

85. Li YS, Zhang FJ, Zeng C, Luo W, Xiao WF, Gao SG, et al. Autophagy in osteoarthritis. Joint Bone Spine. 2016; 83(2):143-8.

86. Onal M, Piemontese M, Xiong J, Wang Y, Han L, Ye S, et al. Suppression of autophagy in osteocytes mimics skeletal aging. J Biol Chem. 2013; 288(24):17432-40.

87. Xiu Y, Xu H, Zhao C, Li J, Morita Y, Yao Z, et al. Chloroquine reduces osteoclastogenesis in murine osteoporosis by preventing TRAF3 degradation. J Clin Invest. 2014; 124(1):297-310.

88. Yao W, Dai W, Jiang L, Lay EY, Zhong Z, Ritchie RO, et al. Sclerostin-antibody treatment of glucocorticoid-induced osteoporosis maintained bone mass and strength. Osteoporos Int. 2016; 27(1):283-94.

89. Liu F, Fang F, Yuan H, Yang D, Chen Y, Williams L, et al. Suppression of autophagy by FIP200 deletion leads to osteopenia in mice through the inhibition of osteoblast terminal differentiation. J Bone Miner Res. 2013;28(11):2414-30.

90. Almeida M, O'Brien CA. Basic biology of skeletal aging: role of stress response pathways. J Gerontol A Biol Sci Med Sci. 2013; 68(10):1197-208.

91. Wu Q, Zhong ZM, Pan Y, Zeng JH, Zheng S, Zhu SY, et al. Advanced oxidation protein products as a novel marker of oxidative stress in postmenopausal osteoporosis. Med Sci Monit. 2015; 21:2428-32.

92. Yang Y, Zheng X, Li B, Jiang S, Jiang L. Increased activity of osteocyte autophagy in ovariectomized rats and its correlation with oxidative stress status and bone loss. Biochem Biophys Res Commun. 2014; 451(1):86-92.

93. Zhang L, Guo YF, Liu YZ, Liu YJ, Xiong DH, Liu XG, et al. Pathway-based genome-wide association analysis identified the importance of regulation-of-autophagy pathway for ultradistal radius BMD. J Bone Miner Res. 2010; 25(7):1572-80 